\title{
Nanoscale Track Diameter and Hydrogen Yield: Dependence upon Charge State of Incident Ion on Polystyrene
}

\author{
D. P. Gupta ${ }^{1}$, R. S. Chauhan ${ }^{2}$, Shyam Kumar ${ }^{3}$, P. K. Diwan ${ }^{3}$, S. A. Khan ${ }^{4}$, Ambuj Tripathi ${ }^{4}$, \\ Santanu Ghosh ${ }^{5}$, V. K. Mittal ${ }^{6}$ \\ ${ }^{1}$ Department of Applied Sciences, Chitkara Institute of Engineering and Technology, Chandigarh, India; ${ }^{2}$ Department of Physics, \\ RBS College, Agra, India; ${ }^{3}$ Department of Physics, Kurukshetra University, Kurukshetra, India; ${ }^{4}$ Inter University Accelerator Centre, \\ New Delhi, India; ${ }^{5}$ Department of Physics, Indian Institute of Technology, New Delhi, India; ${ }^{6}$ Department of Physics, Punjabi Uni- \\ versity, Patiala, India. \\ Email: gupta.devpriya@gmail.com
}

Received October $17^{\text {th }}, 2012$; revised November $29^{\text {th }}, 2012$; accepted December $13^{\text {th }}, 2012$

\begin{abstract}
The study of radiation damage of high- molecular weight substances due to $\mathrm{MeV}$ ion interactions is of interest for engineering and scientific applications. In the present study polystyrene (PS) was irradiated with ${ }^{107} \mathrm{Ag}$ ions of three different charge states (q) $11^{+}, 14^{+}$and $25^{+}$and of $130 \mathrm{MeV}$ energy. The emission of hydrogen from PS was monitored as a function of the incident ion fluence. The experimental results showed that the hydrogen depletion per incident ion from PS varies as $\mathrm{q}^{\mathrm{n}}$, where $\mathrm{n}$ was found to be 2.1 as compared to the value 2.7 to 3.0 reported in the literature. Radii of the nanometric damaged zones or ion tracks formed were analyzed from the slope of the hydrogen depletion versus ion fluence curves as a function of charge state of incident ion. These have values between $3.2-6.8 \mathrm{~nm}$. These radii were found to depend upon the charge state of the incident ion and vary as $\mathrm{q}^{\mathrm{m}}$, where $\mathrm{m}$ has the value 0.9 .
\end{abstract}

Keywords: Polystyrene; Heavy Ions; Ion Fluence; Hydrogen Depletion Cross-Section; Track Radius

\section{Introduction}

When the charged particles like electrons, heavy ions or radiations like $\gamma$ rays with sufficient energy (MeV's energy) pass through a solid, they transfer their energy, mainly through electronic ionization and excitation, of the constituent atoms and molecules [1]. In non-conducting polymeric materials, part of this deposited energy causes chemical breakdown leading to the ejection of various atomic, molecular or gaseous species from the material [2]. As a result, localized regions of extensive chemical and structural transformations due to radiation damage are formed along the ion paths. This causes creation of a so called ion track (a nanometric size cylindrical amorphized zone) $[3,5,6]$ corresponding to each incident ion. The ion-tracks may be used to modify material properties in the nanometer to micrometer scale.

In the recent years various experimental techniques have progressed for the characterization of this nano scale region of very high energy deposition created by energetic ion beams [3-6]. Steckenreiter et al. [3] studied the $\mathrm{MeV} \mathrm{Kr}$ and Mo ion induced modifications in polyethylene terephthalate (PET) and deduced the ion track radius by considering the Fourier transform infra red absorbance measurements. Apel et al. [4] predicted the ion track dimensions in $1-11.6 \mathrm{MeV} / \mathrm{u}{ }^{238} \mathrm{U}$ irradiated PET using a controlled track etch technique. The use of surface microscopy tools [5] is another contemporary technique for the visualization of the nanoscale modified zone. Partial pressure studies of various gasses emitted from $180 \mathrm{MeV} \mathrm{Ag}$ ion irradiated PET using quadrapole mass analyzer also revealed the ion track radii with good accuracy [6].

Mittal et al. [7] showed the possibility of analyzing ion track dimensions by monitoring hydrogen ion yield from the nanosize cylindrical zones. The yield of $\mathrm{H}^{+}$was found to vary as $\mathrm{q}^{\sim 3}$ following the bombardment by 0.5 $\mathrm{MeV} / \mathrm{u}$ ions from ${ }^{127} \mathrm{I}$ to ${ }^{205} \mathrm{Tl}$ on a $\mathrm{C}$ target [8]. Similarly when 0.5 to $1.5 \mathrm{MeV} / \mathrm{u}$ ions from ${ }^{32} \mathrm{~S}$ to ${ }^{127} \mathrm{I}$ were bombarded on $\mathrm{C}$ and $\mathrm{Au}$ foils [9] under poor vacuum conditions or presumably due to absorbed water deposited on the surface, the yield of $\mathrm{H}^{+}$was found to vary as $\mathrm{q}^{\sim 3}$. A $\mathrm{q}^{\cong} 3$ dependence of the $\mathrm{H}^{+}$ion yield from $\mathrm{C}$ target after low energy $116 \mathrm{keV}{ }^{208} \mathrm{Tl}$ ions bombardment was observed by Brunelle et al. [10]. The yield of molecular species were also found to vary as $\mathrm{q}^{3-4}$ when samples 
such as phenylalanine, coronene etc. were bombarded with swift heavy ions $[11,12]$. Similarly when polypropylene (PP) and PET were bombarded with $130 \mathrm{MeV}$ ${ }^{107} \mathrm{Ag}$ ions, the yield dependence of hydrogen was found to vary as $\mathrm{q}^{2.98}$ for the PP and $\mathrm{q}^{1.94}$ for the PET [13]. Bitensky et al. [14] developed a model based on Coulomb explosion of the microscopic charge domain around the point of primary ion impact and predicted a $\mathrm{q}^{3}$ dependence of the $\mathrm{H}$ ion yield. The energy and angular distribution of the ejected ions from $\mathrm{MeV}^{127} \mathrm{I}^{\mathrm{q}+}(\mathrm{q}=17-32)$ impacted $\mathrm{Au}$ and $\mathrm{C}$ foils have been studied by Most et al. $[15,16]$ on the basis of Monte Carlo calculations. A slight increase in the mean energies and emission angle with the charge state was reported. However, they did not report any functional dependence of the hydrogen ion yield on the charge state of the incident ion. Using a perturbbative convolution approximation, based upon the first order perturbation theory formulated using Bloch's stopping power results and a simple scaling law, Schiwietz and Grande $[17,18]$ have been able to show that the stopping power depends on the charge state of the incident ion.

Polystyrene is a macromolecular plastic material. It is a vinyl polymer consisting of a long hydrocarbon chain, with a phenyl group attached to every other carbon atom. It is hard and used for packaging, foam insulation, appliances, housewares, toys etc.

Saturated core model was proposed by Davenas et al. [19] which showed exponential decrease of hydrogen yield from PS when irradiated with $700 \mathrm{KeV} \mathrm{He}$. In particular PS suffers mainly cross-linking, formation carbon clusters along the region of energy deposition by incident ions [5,20,21].

The objective of this work was to monitor hydrogen evolved from polystyrene due to the fast heavy ion irradiation in order to obtain information on ion-polymer interaction. The radii of the damaged zones or so called ion tracks formed in it have also been analyzed as a function of the charge state of the incident ion from the hydrogen depletion data.

\section{Experimental Arrangements}

In this recent investigation the Irradiation facilities at the Inter University Accelerator Centre, New Delhi were used. Thin foils of PS having thicknesses between 6 - 20 $\mu \mathrm{m}$ were bombarded with ion beams of ${ }^{107} \mathrm{Ag}$ of charge states $11^{+}, 14^{+}$and $25^{+}$and of energy $130 \mathrm{MeV}$ from a 15UD Pelletron [22] at room temperature. The beam currents in all the experiments were kept at $\approx 1$ particle nano-ampere to prevent the degradation of the target due to the heating effects. The area scanned by the incident beam on the polymer surface was about $0.09 \mathrm{~cm}^{2}$ and the tilt angle of the target with respect to the beam direction was at $15^{\circ}$. During irradiation the hydrogen recoils from the films were detected in a silicon surface barrier detector having a depletion depth of $1 \mathrm{~mm}$ kept at $45^{\circ}$ with respect to the beam direction. The energy resolution of the silicon surface barrier detector used was about 30 $\mathrm{keV}$ for $5.48 \mathrm{MeV} \alpha$-particles. Heavier elements, molecules and radicals emitted during the ion irradiation were stopped with the help of a polypropylene film of thickness $26 \mu \mathrm{m}$ kept before the detector. Further experimenttal details can be found in our earlier work $[7,13]$.

\section{Results}

When the ion beam impinges on the PS surface, ejection of hydrogen starts. Figure 1 shows two characteristic hydrogen recoil spectra at the fluence of $1.62 \times 10^{13}$ ions $/ \mathrm{cm}^{2}$ (lower curve) and $2.47 \times 10^{11}$ ions $/ \mathrm{cm}^{2}$ (upper curve) for ${ }^{107} \mathrm{Ag}$ of charge state $11^{+}$on PS. The hydrogen evolving from a depth of $10-100 \mathrm{~nm}$ is shown as a function of ion fluence for different charge states for PS in Figure 2. For comparison, curves are shown in Figure 3 from a depth of 1000 to $1500 \mathrm{~nm}$. In this figure these curves were almost overlapping, so the $\mathrm{H}$ loss curve corresponding to $11^{+}$charge state was multiplied by 4 while the curve corresponding to charge state $25^{+}$is divided by 4 for the present figure.

The hydrogen areal density as a function of ion fluence (Figure 2) was fitted using two equations [7] in two different regimes

$$
\begin{aligned}
& N_{1}(\varphi)=N_{1,0} \exp \left(-\sigma_{1} \varphi\right) \\
& N_{2}(\varphi)=N_{2,0} \exp \left(-\sigma_{2} \varphi\right)
\end{aligned}
$$

Where $\varphi\left(\mathrm{cm}^{-2}\right)$ is the ion fluence, $\sigma_{1}$ and $\sigma_{2}$ are the hydrogen depletion cross-sections in $\mathrm{cm}^{2}$ and $N_{1,0}$ and $N_{2,0}$ are constants. This fitting is shown in Figure 2 as solid lines. Here it is understood that the hydrogen emanation takes place from a cylindrical damage zone [2]. It is also important to notice that at some ion fluence the hydrogen emanation diminishes. This can be attributed to the overlapping of the damage zones which starts at this ion fluence. The nature of hydrogen loss curves then changes resulting in a curve of different slope. This is because of the fact that the whole ion beam exposed region was modified due to hydrogen loss and ion beam induced modifications. The intersection of the two lines (as shown in Figure 2) represents the approximate fluence corresponding to which an overlap [6,7] of ion damage zones takes place. The values of $\sigma_{1}, N_{1,0}, \sigma_{2}$ and $N_{2,0}$ as a function of incident ion charge state determined in the present experiment are listed in Table 1.

\subsection{Hydrogen Depletion per Incident Ion}

The average amount of hydrogen depleted per incident 


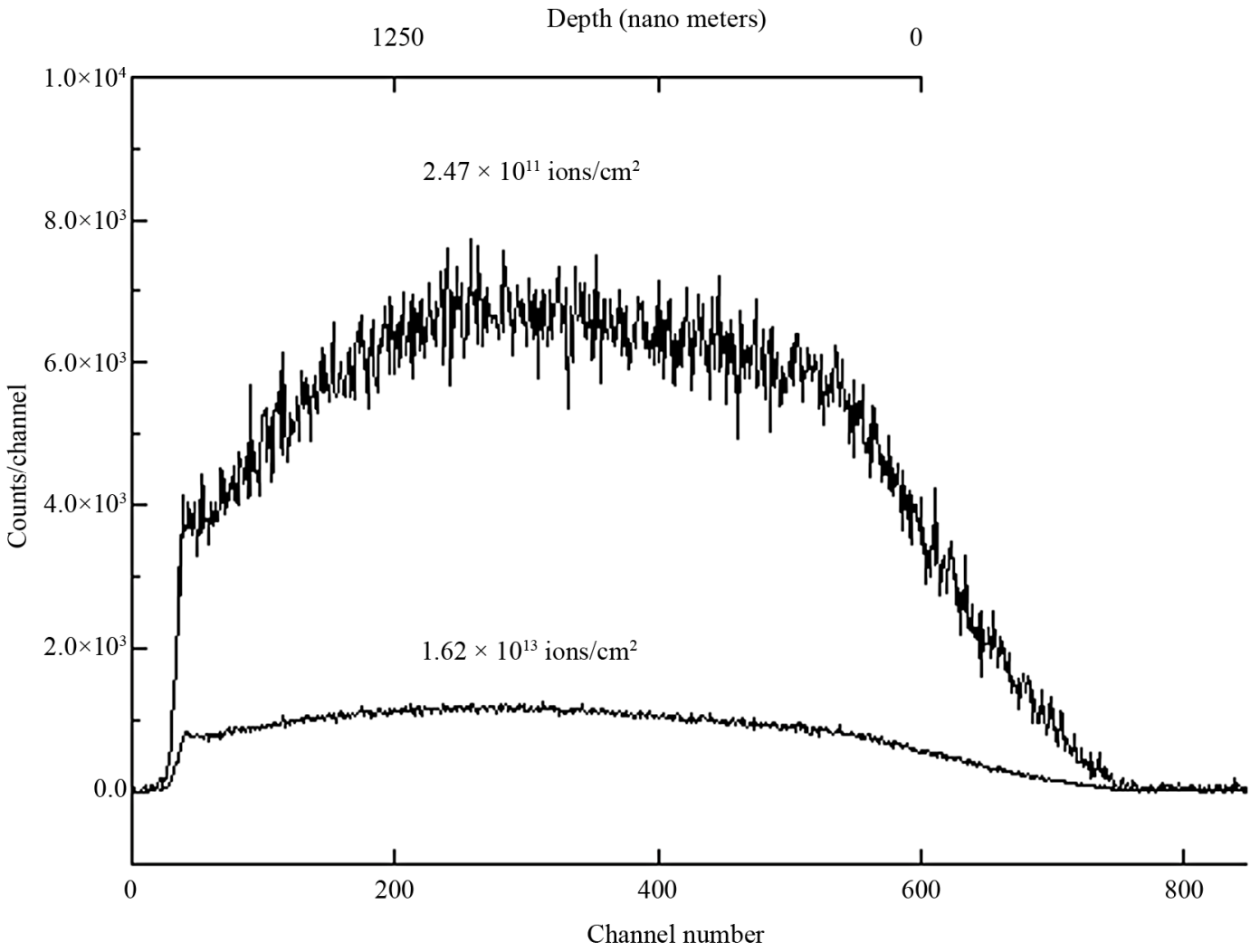

Figure 1. Hydrogen depletion spectra at the fluence of $2.47 \times 10^{11}$ ions $/ \mathrm{cm}^{2}$ (upper cfurve) and $1.61 \times 10^{13}$ ions $/ \mathrm{cm}^{2}($ lower curve) for $130 \mathrm{MeV}^{107} \mathrm{Ag}^{11+}$ on PS. The zero depth is at $\sim 600$ channels and 1 channel corresponds to $\sim 3.1 \mathrm{~nm}$.

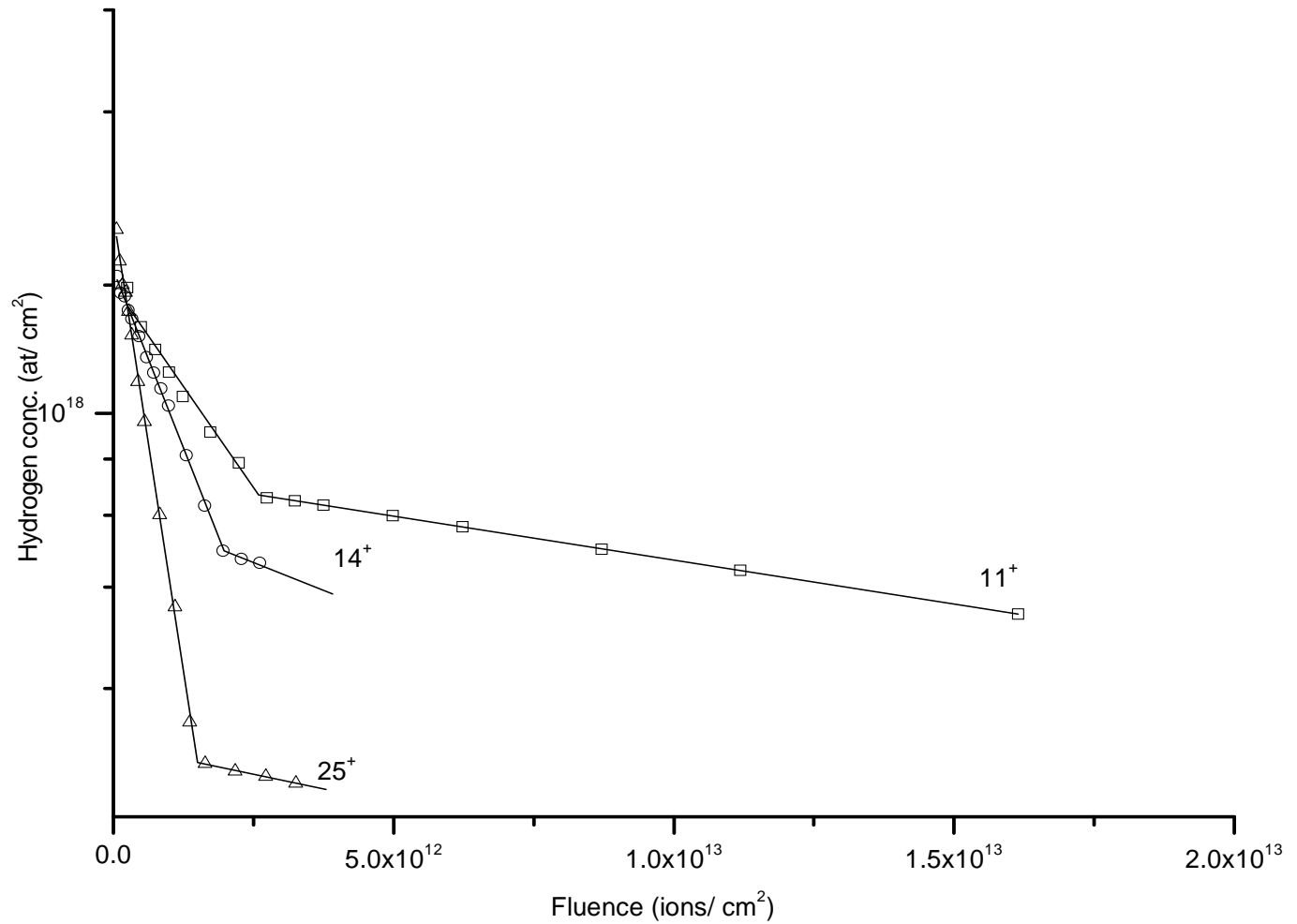

Figure 2. Hydrogen areal concentration (in at $/ \mathrm{cm}^{2}$ ) up to a depth of $\sim 100 \mathrm{~nm}$ versus fluence for $11^{+}, 14^{+}$and $25^{+107} \mathrm{Ag}$ ions of $130 \mathrm{MeV}$ energy bombarded on PS. 


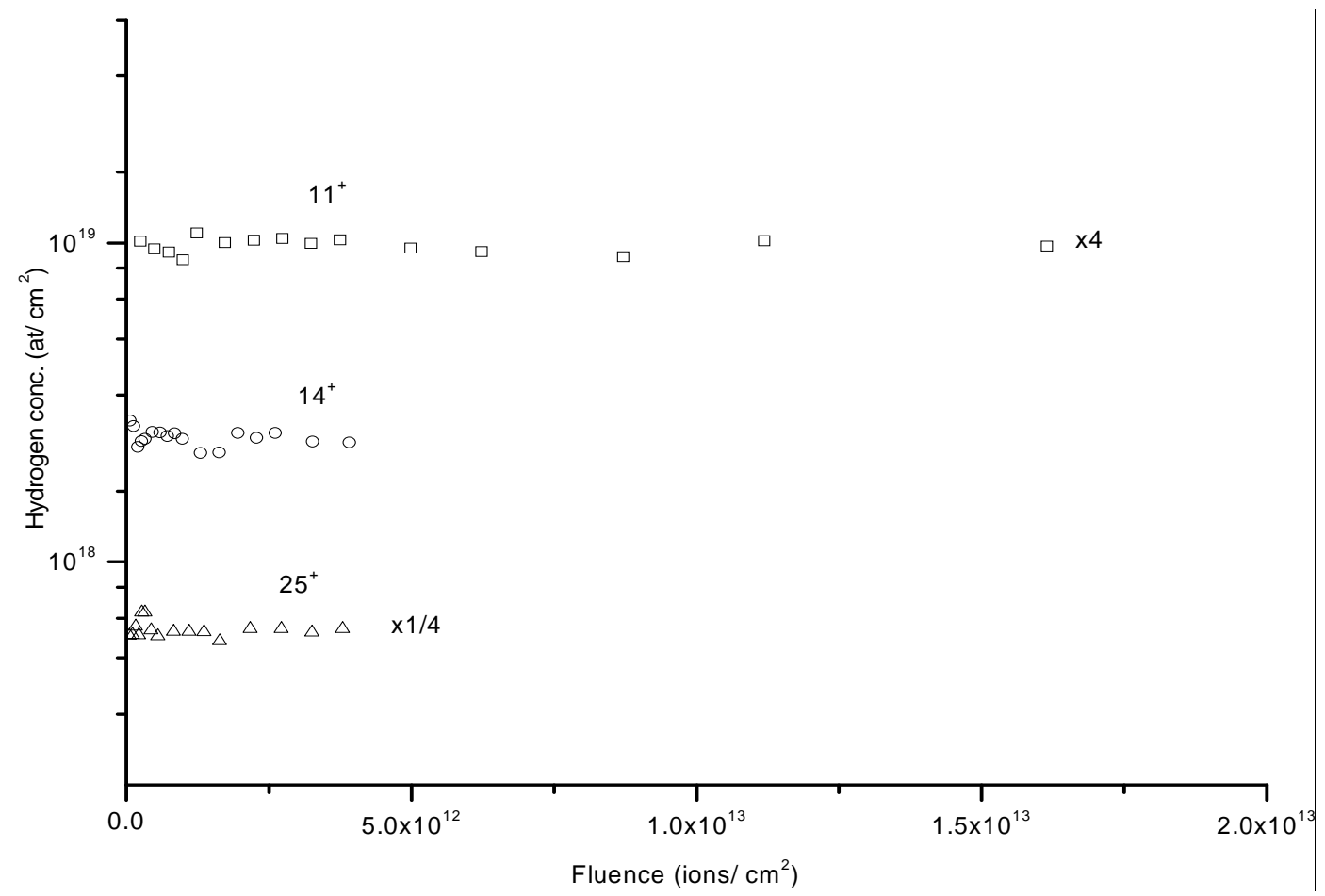

Figure 3. Hydrogen areal concentration (in at $/ \mathrm{cm}^{2}$ ) from a depth of 1000 to $1500 \mathrm{~nm}$ versus fluence for $11^{+}, 14^{+}$and $25^{+} 107 \mathrm{Ag}$ ions of $130 \mathrm{MeV}$ energy bombarded on PS. The $11^{+}$curve is multiplied by 4 while the curve corresponding to charge state $25^{+}$ is divided by 4 .

Table 1. Hydrogen emission cross sections $\sigma_{1}$ and $\sigma_{2}$; hydrogen concentrations $N_{1,0}$, and $N_{2,0}$ measured in the present work for PS.

\begin{tabular}{cccccc}
\hline \multirow{2}{*}{ Polymer } & $\begin{array}{c}\text { Charge } \\
\text { state }\end{array}$ & \multicolumn{2}{c}{ First curve } & \multicolumn{2}{c}{ Second curve } \\
\cline { 3 - 6 } & $11^{+}$ & $\begin{array}{c}\sigma_{1}\left(\mathrm{~cm}^{2}\right) \\
\times 10^{-13}\end{array}$ & $\begin{array}{c}N_{1,0}\left(\mathrm{~cm}^{-2}\right) \\
\times 10^{18}\end{array}$ & $\begin{array}{c}\sigma_{2}\left(\mathrm{~cm}^{2}\right) \\
\times 10^{-13}\end{array}$ & $\begin{array}{c}N_{2,0}\left(\mathrm{~cm}^{-2}\right) \\
\times 10^{18}\end{array}$ \\
\hline \multirow{3}{*}{ PS } & $14^{+}$ & 5.68 & 1.67 & 0.35 & 0.79 \\
& $25^{+}$ & 14.52 & 2.19 & 0.88 & 0.69 \\
\hline
\end{tabular}

ion can be calculated by multiplying hydrogen emission cross-section $\sigma_{1}$ with the hydrogen concentration $N_{1,0}$ [6]. These values were calculated for different charge states and are also given in Table 2. The hydrogen released as a function of charge state of the incident ion is shown in Figure 4.

\subsection{Track Radius}

The radius of the effective damaged zone or the ion track was calculated from the hydrogen depletion cross-sections $\sigma_{1}$ using the relation reported earlier [7].

$$
r_{\text {track }}=\left(\sigma_{1} / \pi\right)^{1 / 2}
$$

The ion track radii (in nanometers) calculated for PS bombarded with $130 \mathrm{MeV}{ }^{107} \mathrm{Ag}$ ions of different charge states are given in Table 2 and are also shown in Figure
5. As is evident from Table 2 , the track radii varied between $\sim 3.2 \mathrm{~nm}$ and $\sim 6.8 \mathrm{~nm}$.

\section{Discussions}

The hydrogen depletion vs. fluence curves for two different depth ranges are shown in Figures 2 and 3. It is evident from Figsures $\mathbf{2}$ and $\mathbf{3}$ that when an ion of a particular charge state is incident upon the surface of PS its charge state equilibrates $[23,24]$ in the near surface region (say up to $\sim 10-20 \mathrm{~nm}$ ). Since the resolution of hydrogen profiling in the present experiment was about 50 $\mathrm{nm}$, therefore, we should see this difference near the surface region only. It is expected that if we take the hydrogen counts from up to a depth of, say $100 \mathrm{~nm}$, we could observe the effect due to charge state of the incident ion as is evident from Figure 2, where we have taken the hydrogen ions coming up to a depth of $10-100 \mathrm{~nm}$. In contrast the yield of hydrogen become independent of the charge state of the incident ion if we consider the hydrogen ions coming from within a depth of about 1000 to $1500 \mathrm{~nm}$ as shown in Figure 3.

It is also obvious from Figures $\mathbf{4}$ and $\mathbf{5}$ that emission of hydrogen as well as track radii depend strongly upon the charge state of the incident ion. This behavior is in accordance with the results reported earlier by Schiwietz and Grande $[17,18]$ that the electronic stopping power depends upon the charge state of the incident ion. The 
Table 2. Hydrogen emission per incident ion and track radius calculated for different charge states of $130 \mathrm{MeV}^{107} \mathrm{Ag}$ ions on PS. $4^{\text {th }}$ and $6^{\text {th }}$ column of this table show the fitted equations for hydrogen released/incident ion and track radius calculated for different charge states respectively.

\begin{tabular}{cccccc}
\hline \multirow{2}{*}{ Polymer } & $\begin{array}{c}\text { Charge } \\
\text { state }\end{array}$ & Track radius (nm) & $r=\beta \mathrm{q}^{\mathrm{m}}$ & $\begin{array}{c}\text { Hydrogen released/incident ion (y) } \\
\times 10^{6}\end{array}$ & $\mathrm{Y}=\alpha \mathrm{q}^{\mathrm{n}}$ \\
\hline \multirow{3}{*}{ PS } & $11^{+}$ & 3.2 & $\beta=3.83 \times 10^{-10}$ & 0.54 & $\alpha=3.37 \times 10^{3}$ \\
& $14^{+}$ & 4.3 & $\mathrm{~m}=0.9$ & 1.00 & $\mathrm{n}=2.1$ \\
& $25^{+}$ & 6.8 & & 3.18 & \\
\hline
\end{tabular}

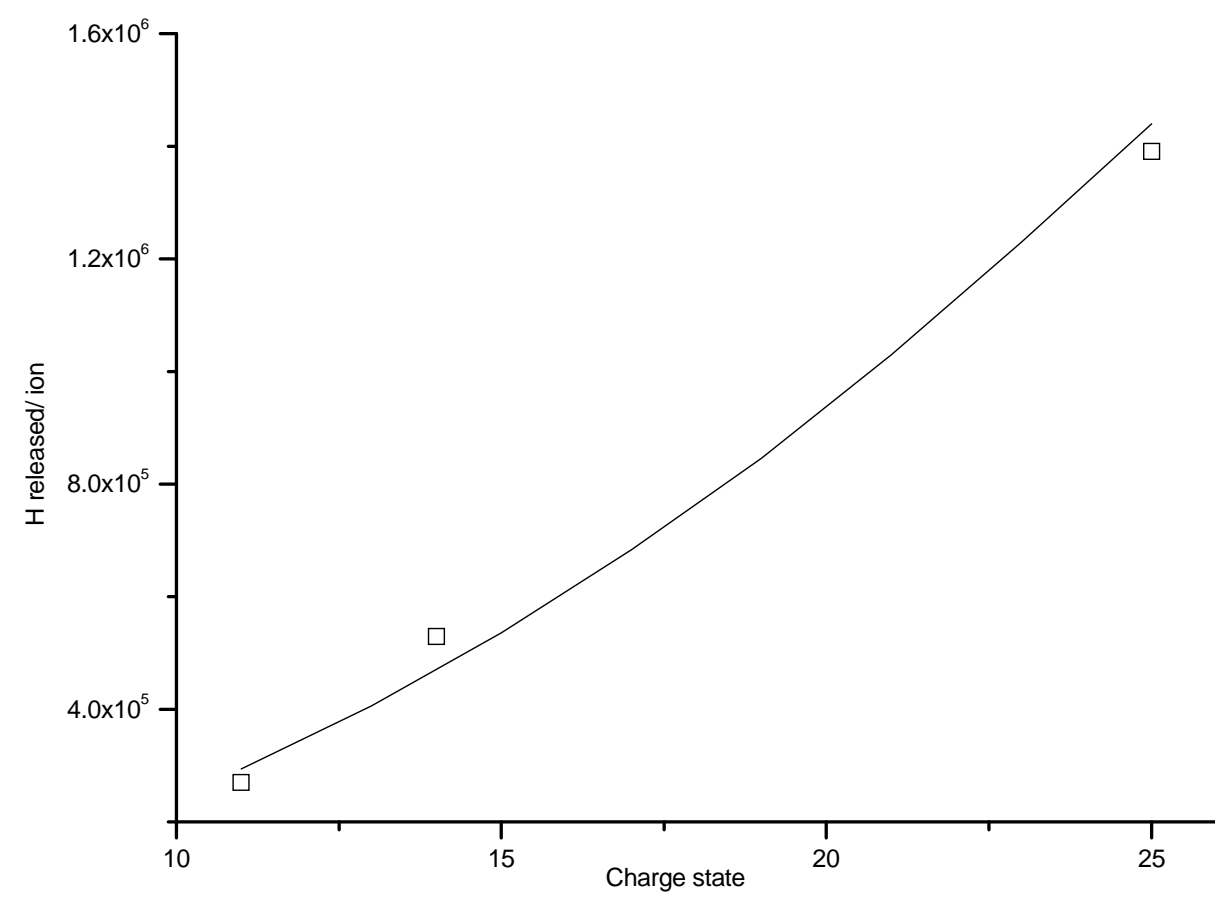

Figure 4. Hydrogen depletion (evolving from a depth of 10 - $100 \mathrm{~nm}$ ) per incident ion as a function of charge state of the incident ion for PS.

hydrogen depletion per incident ion in the present irradiation of PS with $130 \mathrm{MeV}{ }^{107} \mathrm{Ag}$ ions of different charge states were fitted with an equation of the type $y=$ $\alpha \mathrm{q}^{n}$ (Figure 4), where $\mathrm{q}$ is the charge on the incident ion. The value of the exponent $\mathrm{n}$ is found to be $\sim 2.1$ whereas Wien et al. [12] reported this value as 2.7. Therefore, we may conclude that the charge state of the projectile incident at the surface of PS strongly influences ionization of hydrogen due to different electronic stopping power [17, 18] but the force driving desorption of the hydrogen ions was less q-dependent as compared to the predictions of Coulomb explosion model [14]. Halhammer et al. [25] also reported the charge state dependence of projectiles guiding through nanocapillaries in PET.

If we compare the value of exponent $n=2.1$ from the present worked out problem to that reported earlier $n=$ 2.98 for PP (13) we can easily conclude that the chances of hydrogen depletion are less from $\mathrm{CH}_{2}$ bonds. Fujimoto et al. [26] suggested that the hydrogen released as $\mathrm{H}^{+}$ from $\mathrm{CH}$ or $\mathrm{CH}_{2}$ may recombine with dangling carbon bonds. The rate of hydrogen depletion, from polymers like PP, where $\mathrm{CH}_{3}$ type bonds are present, is therefore, higher in comparison to PS.

It is also evident from Table 2 that the radii of ion tracks formed in PS depend upon the charge state of the incident ion. When the charge state of the incident ion was doubled aproximately (from 11 to 25), the radius of the ion track also increased by a factor of 2 . The ion track radii calculated for the different charge states were fitted with an equation of the type $r=\beta \mathrm{q}^{m}$ (Figure 5), where q is the charge of incident ion and the exponent $m$ was found to be 0.9 . The radii of ion tracks formed in different ion-polymer combinations as reported by different workers along with present measurements are shown in Table 3. It is evident from this table that our measurements are comparable with the values reported in literature.

\section{Conclusion}

Monitoring of excitation products like hydrogen from 


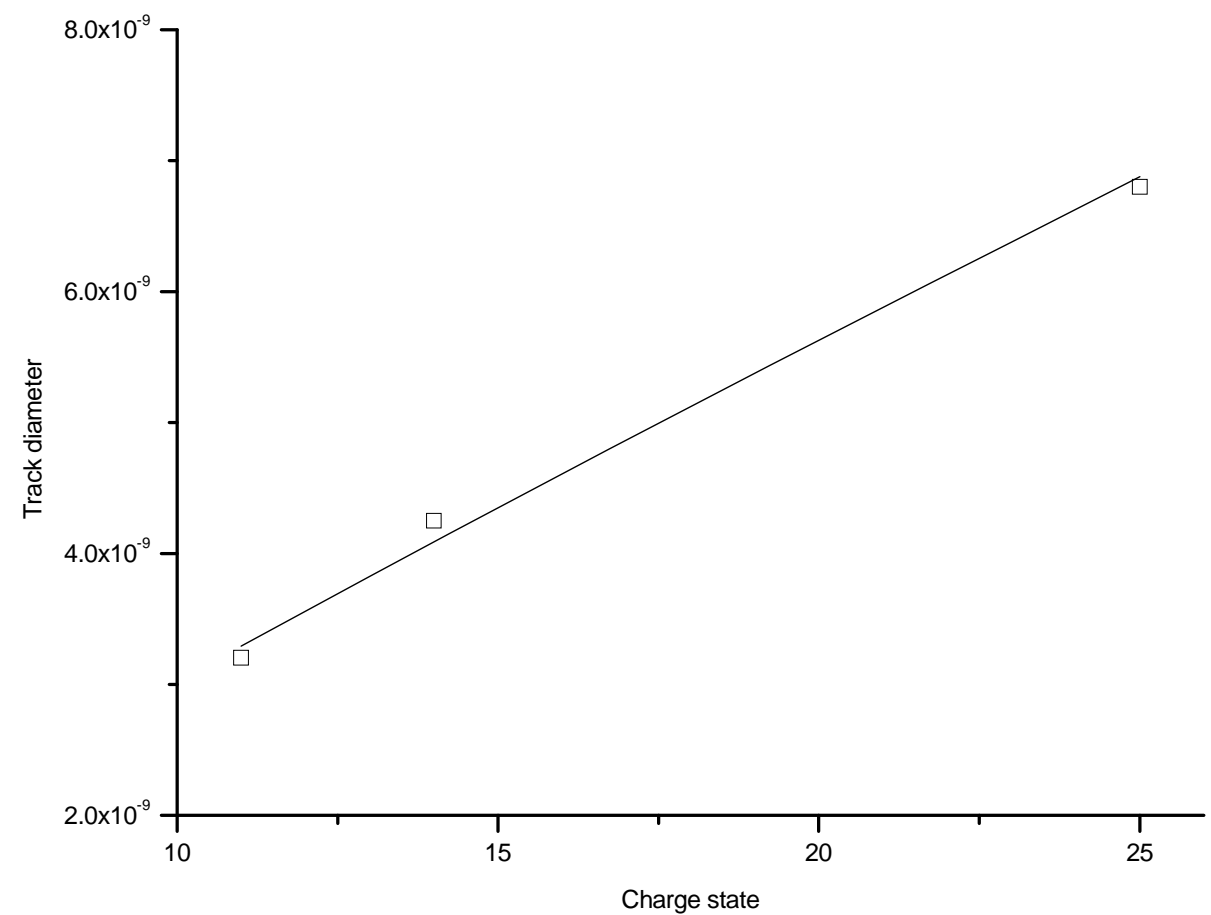

Figure 5. Track radii as a function of charge state of the incident ion for PS.

Table 3. Ion track radii based upon hydrogen emission during irradiation of polymers as measured in the present investigation along with the values reported previously.

\begin{tabular}{cccc}
\hline Polymer & Source of data & Ions and energy & Track radius $r(\mathrm{~nm})$ \\
\hline PS & Present investigation & $130 \mathrm{MeV}^{107} \mathrm{Ag}^{+11},{ }^{107} \mathrm{Ag}^{+14}$ and ${ }^{107} \mathrm{Ag}^{+25}{ }^{107} \mathrm{Ag}^{+25}$ & $3.2-6.8$ \\
PET & {$[1]$} & $8.6 \mathrm{MeV} / \mathrm{u} \mathrm{Kr}$ & 3 \\
PET & {$[2]$} & $11.6 \mathrm{MeV} / \mathrm{u}^{238} \mathrm{U}$ & 7.5 \\
PS & {$[3]$} & $130 \mathrm{MeV}{ }^{84} \mathrm{Kr}^{+18}$ & 5.6 \\
PET & {$[4]$} & $180 \mathrm{MeV} \mathrm{Ag}$ & 4 \\
\hline
\end{tabular}

fast heavy ion irradiated polymers is an important tool to probe track dimensions. The hydrogen depletion rate from heavy ion irradiated polymers decreases after certain ion fluence when the overlapping of the ion tracks starts and the hydrogen depletion curves tend to flatten at this ion fluence. The removal of hydrogen when ${ }^{107} \mathrm{Ag}$ ions are bombarded on polystyrene is influenced strongly by the charge state of the incident ions. It varies as $\mathrm{q}^{\mathrm{n}}$, where $\mathrm{n}$ is 2.1 as compared to $\mathrm{n}=2.98$, reported earlier for PP. This is a clear Indicative that hydrogen evolution is $\mathrm{C}-\mathrm{H}$ bond type dependent as the polymer PP contains $\mathrm{CH}_{3}$ type bonds in comparison to $-\mathrm{C}-\mathrm{H}-$ and $-\mathrm{CH}_{2}$ - type bons of PS. The rate of hydrogen loss is less from PS. The radii of damaged zones also depend upon the charge state of the incident ion and were found to vary as $\mathrm{q}^{\mathrm{m}}, \mathrm{m}$ being 0.9 .

\section{Acknowledgements}

The authors are grateful to the Director and Pelletron machine staff at the IUAC, New Delhi for providing the required facilities for this study. They are also thankful to Fouran Singh for providing valuable help at various stages of this experiment. One of the authors DPG expresses his thanks to Dr. (Mrs.) Madhu Chitkara for her constant motivation and encouragement.

\section{REFERENCES}

[1] H. G. H. Kumar, R. D. Mathad and S. Ganesh, "ElectronBeam-Induced Modifications in High-Density Polyethylene," Brazilian Journal of Physics, Vol. 41, No. 1, 2011, pp. 7-14.

[2] D. P. Gupta, S. Kumar, P. C. Kalsi, V. K. Manchanda and V. K. Mittal, " $\gamma$-Ray Modifications of Optical/Chemical Properties of a PVC Polymer," Radiation Effects and Defects in Solids, Vol. 167, No. 2, 2012, pp. 149-156.

[3] T. Steckenreiter, E. Balanjat, H. Fuess and C. Trautmann, "Chemical Modifications of PET Induced by Swift Heavy Ions," Nuclear Instruments and Methods in Physics Research Section B, Vol. 131, No. 1-4, 1997, pp. 159-166. 
[4] P. Apel, A. Schulz, R. Spohr, C. Trautmann and V. Vutsadakis, "Tracks of Very Heavy Ions in Polymers," Nuclear Instruments and Methods in Physics Research Section B, Vol. 131, No. 1-4, 1997, pp. 55-63.

[5] S. Tsukuda, S. Seki, S. Tagawa, S. Sugimoto and M. Sugimoto, "Effect of Ion Beam Energy and Polymer Weight on the Thickness of Nanowires Produced by Ion Bombardment of Polystyrene Thin Films," Applied Physics Letters, Vol. 87, No. 23, 2005, p. 233119.

[6] D. K. Avasthi, J. P. Singh, A. Biswas and S. K. Bose, "Study on Evolution of Gases from Mylar under Ion Irradiation," Nuclear Instruments and Methods in Physics Research Section B, Vol. 146, No. 1-4, 1998, pp. 504-508.

[7] V. K. Mittal, S. Lotha and D. K. Avasthi, "Hydrogen Loss under Heavy Ion Irradiation in Polymers," Radiation Effects and Defects in Solids, Vol. 147, No. 3, 1999, pp. 199-209.

[8] S. Della-Negra, J. Depauw, H. Joret and Y. Le-Beyec, " $\mathrm{H}^{+}$Ion Emission from Solid Carbon Foil Bombarded by Multicharged Primary Ions at $0.5 \mathrm{MeV} / \mathrm{u}$ and $0.5 \mathrm{KeV} / \mathrm{u}$," IPN Annual Report, 1990, p. 138.

[9] Brunelle, S. Della-Negra, J. Depauw, H. Joret, Y. Le Beyec and K. Wien, "Equilibrium Charge State of Fast Heavy Ions in Solids Measurements of Post-Ionizatton Effects," Nuclear Instruments and Methods in Physics Research Section B, Vol. 43, No. 4, 1989, pp. 484-489.

[10] Brunelle, S. Della-Negra, J. Depauw, H. Joret and Y. Le Beyec, "A Simple Way to Study Secondary Ion Emission by Heavy Multicharged Ions at Medium Energy ( $\simeq 115$ $\mathrm{keV}$. Application to Hydrogen Ion Emission," Nuclear Instruments and Methods in Physics Research Section B, Vol. 43, No. 4, 1989, pp. 586-588.

[11] P. Hakansson, I. Kamensky and B. Sundqvist, "Fast Heavy-Ion Induced Desorption of Biomolecules," Nuclear Instruments and Methods in Physics, Vol. 198, No. 1, 1982, pp. $43-51$.

[12] K. Wien, O. Becker, W. Guthier, S. Della-Negra, Y. Le Beyec, B. Monart, K. G. Standing, G. Maynard and C. Deutsch, "The Charge State Dependence of Desorption. A Way to Study the Energy Transfer to the Surface," International Journal of Mass Spectrometry and Ion Processes, Vol. 78, 1987, pp. 273-304.

[13] D. P. Gupta, R. S. Chauhan, S. Kumar, P. K. Diwan, S. A. Khan, A. Tripathi, D. K. Avasthi and V. K. Mittal, "Dependence of Hydrogen Released on the Charge State of Incident Ions," Radiation Effects and Defects in Solids, Vol. 161, No. 6, 2006, pp. 331-338.

[14] I. Bitensky, E. Parilis, S. Della-Negra and Y. Le Beyek, "Emission of Hydrogen Ions under Multiply Charged Ion Bombardment," Nuclear Instruments and Methods in Physics Research Section B, Vol. 72, No. 3-4, 1992, pp. 380-386.

[15] M. Most, K. Wien, A. Brunelle, S. Della Negra, J. Depauw, D. Jacquet, M. Pautrat and Y. Le Beyec, " $\mathrm{H}_{2}{ }^{+}, \mathrm{H}_{3}{ }^{+}$ and $\mathrm{H}^{-}$Emission by $\mathrm{MeV}$ Ion Impact: Charge State De- pendence of Energy and Angular Distributions," $\mathrm{Nu}$ clear Instruments and Methods in Physics Research Section B, Vol. 164, 2000, pp. 772-784.

[16] M. Most, K. Wien, A. Brunelle, S. Della Negra, J. Depauw, D. Jacquet, M. Pautrat and Y. LeBeyec, " $\mathrm{H}^{+}$Emission by MeV-Ion Impact: Charge State Dependence of Energy and Angular Distributions," Nuclear Instruments and Methods in Physics Research Section B, Vol. 168, No. 2, 2000, pp. 203-214.

[17] G. Schiwietz and P. L. Grande, "Improved Charge-State Formulas," Nuclear Instruments and Methods in Physics Research Section B, Vol. 175, No. 2, 2001, pp. 125-131.

[18] G. Schiwietz and P. L. Grande, "A Unitary Convolution Approxim Ation for the Impact-Parameter Dependent Electronic Energy Loss," Nuclear Instruments and Methods in Physics Research Section B, Vol. 153, No. 1-4, 1999, pp. 1-9.

[19] J. Davenas and P. Thévenard, "Models of the Hydrogen Release from Polymers under Ion Beam Irradiation," Nuclear Instruments and Methods in Physics Research Section B, Vol. 208, 2003, pp. 170-175.

[20] L. Calcagno, R. Percolla and G. Foti, "Ion Track Effects on Gel Formation of Polystyrene," Nuclear Instruments and Methods in Physics Research Section B, Vol. 95, No. 1, 1995, pp. 59-64.

[21] L. Singh, K. S. Samra and R. Singh, "Optical and Structural Modifications in Heavy Ion Irradiated Polystyrene," Journal of Macromolecular Science, Part B, Vol. 46, No. 4, 2007, pp. 749-759.

[22] G. K. Mehta and A. P. Patro, "15 UD Pelletron of the Nuclear Science Centre-Status Report," Nuclear Instruments and Methods in Physics Research Section A, Vol. 268, No. 2-3, 1988, pp. 334-338.

[23] R. Herrmann, C. L. Cocke, J. Ullrich, S. Hagmann, M. Stoeckli and H. Schmidt-Boecking, "Charge-State Equilibration Length of a Highly Charged Ion inside a Carbon Solid," Physical Review A, Vol. 50, No. 2, 1994, pp. 14351444.

[24] S. Winecki, M. P. Stöckli and C. L. Cocke, "Rapid Neutralization and Charge Equilibration of Highly Charged Ions at Grazing Incidence on a Surface," Physical Review $A$, Vol. 56, No. 1, 1997, pp. 538-542.

[25] R. Hellhammer, D. Fink and N. Stolterfoht, "Guiding of Highly Charged Ions through Nanocapillaries in PET: Dependence on the Projectile Energy and Charge," $\mathrm{Nu}$ clear Instruments and Methods in Physics Research Section B, Vol. 261, No. 1-2, 2007, pp. 149-152.

[26] F. Fujimoto, M. Tanaka, Y. Iwata, A. Ootuka, K. Komaki, M. Haba and K. Kobayashi, "Hydrogen Release during Erd Analysis of Hydrogen in Amorphous Carbon Films Prepared by rf-Sputtering," Nuclear Instruments and Methods in Physics Research Section B, Vol. 33, No. 1-4, 1988, pp. 792-794. 